\title{
Investigation of Stress Concentration and Casing Strength Degradation Caused by Corrosion Pits
}

\author{
Wei Yan, Yun Xu, Yi Zhou, and Kongyang Wang \\ State Key Laboratory of Petroleum Resources and Prospecting, China University of Petroleum, Beijing, China \\ Correspondence should be addressed to Wei Yan; yanwei289@126.com
}

Received 21 July 2016; Accepted 15 September 2016

Academic Editor: Ksenija Babic

Copyright ( 2016 Wei Yan et al. This is an open access article distributed under the Creative Commons Attribution License, which permits unrestricted use, distribution, and reproduction in any medium, provided the original work is properly cited.

\begin{abstract}
Downhole casing and tubing are subjected to corrosion in many cases because of the exposure to corrosive environment. A more serious problem is that pitting corrosion occurs in the casing inner surface. Meanwhile, downhole strings are subjected to various forms of mechanical loads, for example, internal pressure load, external collapse load, or both. These loads acting on the corrosion pits will cause stress concentration and degrade the casing strength. Thus, it is essential to evaluate the stress concentration degree reasonably. The SCF (stress concentration factor) is usually used to characterize the degree of stress concentration induced by corrosion pits. This paper presented a comparison on the SCFs regarding the analytical method for a single pit and experimental method for double pits. The results show that the SCF of a single pit depends mainly on the depth of the corrosion pit; however, the SCF of the double pits strongly depends on the pits distance. A correction factor of 1.3 was recommended in the double pits SCF prediction model.
\end{abstract}

\section{Introduction}

Stress concentration is a stress increasing phenomenon in which geometric shapes, such as cavities and grooves, cause stress to change dramatically. The magnification of the stress concentration usually is expressed by the elastic stress concentration factor (SCF). SCF calculation model could be divided into two types: one is considered as a semi-infinite body having a hemispherical pit located on the plane's surface. This problem was systematically presented by Murakami in the 1980s [1], and he gave the analytical solution. Another model is an infinite diameter cylinder with a spherical cavity, where at the weakest section (excluding the spherical cavity) Timoshenko theory can be used [2] to calculate the SCF. Typical corrosion pits in the tubing inner surface are shown in Figure 1, including double hemispherical pits and multiple pits.

Based on the stress distribution calculation model of spherical defect in infinite radius cylinder, as shown in Figure 2, the cross profile diagram is shown in Figure 3.

According to the theory of elasticity, with the infinite boundary problem $(b \rightarrow \infty)$, in $x-y$ plane, excluding the defect, the axial load $\sigma_{z}$ can be calculated as follows [2]:

$$
\sigma_{z}=\sigma\left[1+\frac{4-5 \nu}{2(7-5 v)} \frac{a^{3}}{r^{3}}+\frac{9}{2(7-5 \nu)} \frac{a^{5}}{r^{5}}\right],
$$

where $v$ is Poisson's ratio; $a$ is the radius of the pit; $r$ is the distance to the center of the corrosion pit.

Maximum stress $\sigma_{z \text {, max }}$ appears on the intersecting circumference between the cross sections through the center of the pit and the surface of the pit. When $r=a$, the maximum axial stress is

$$
\sigma_{z, \max }=\frac{27-15 \nu}{2(7-5 v)} \sigma .
$$

The stress concentration factor can be defined as

$$
K=\frac{27-15 v}{2(7-5 v)} \text {. }
$$

This is different from the plane stress/strain problems; stress is related to Poisson's ratio; the relationship between stress concentration factor and Poisson's ratio is shown in Figure 4. However, Poisson's ratio of steel is between 0.25 and 0.3 , which has a small influence on stress concentration factor.

Researchers divide the spherical corrosion defects into three categories: shallow-spherical, exact-hemispherical, and 


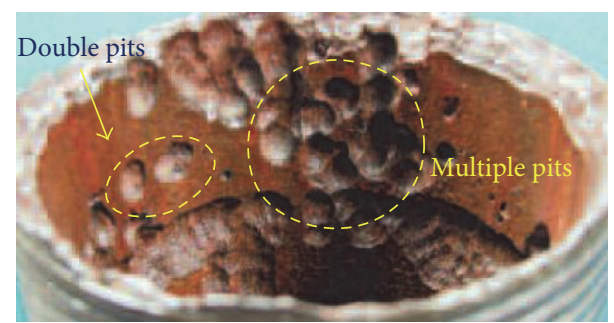

FIgURE 1: Typical pitting corrosion in tubing inner surface.

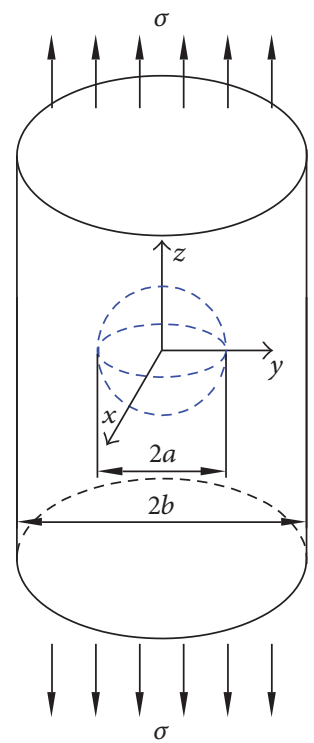

FIGURE 2: A circular cylinder with a center spherical cavity.

deep-spherical defects. The term shallow-spherical refers to the depth of the pit less than the openings radius of the pit; that is $h<a$; the term exact-hemispherical refers to $h=a$; and the term deep-hemispherical refers to $h>a$. Sun et al. [3] calculated stress concentration factors of three types of corrosion pits, on the basis of the stress concentration factor calculation method of hemispherical pit in casing proposed by Wang [4]. It needs to be stressed that the three models of stress concentration plot curves are similar except for a slight difference in the case of small depth of pits. This paper used the exact-hemispherical $(h=a)$ model to give a demonstration (Figure 5).

The revised model of an exact-hemispherical defect SCF is given as follows $[5,6]$ :

$$
K_{c, \text { hemisphere }}=\frac{[(27-15 v) /(14-10 v)]}{1-k_{1}\left(a^{3} / t^{3}\right)-k_{2}\left(a^{5} / t^{5}\right)},
$$

where

$$
\begin{aligned}
& k_{1}=-\frac{27-15 v}{14-10 \nu} \cdot \frac{5-4 v^{2}}{(6-4 v)(1+v)}+2.5, \\
& k_{2}=\frac{27-15 v}{14-10 v} \cdot \frac{5-4 v^{2}}{(6-4 \nu)(1+v)}-1.5,
\end{aligned}
$$

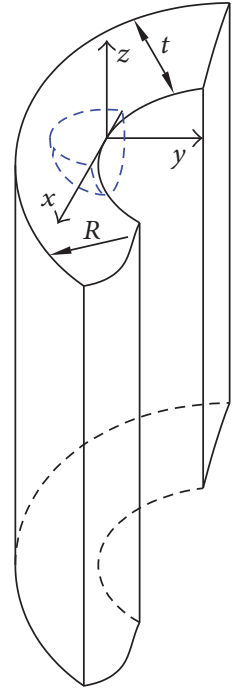

FIGURE 3: Spherical cavity in the casing inner surface.

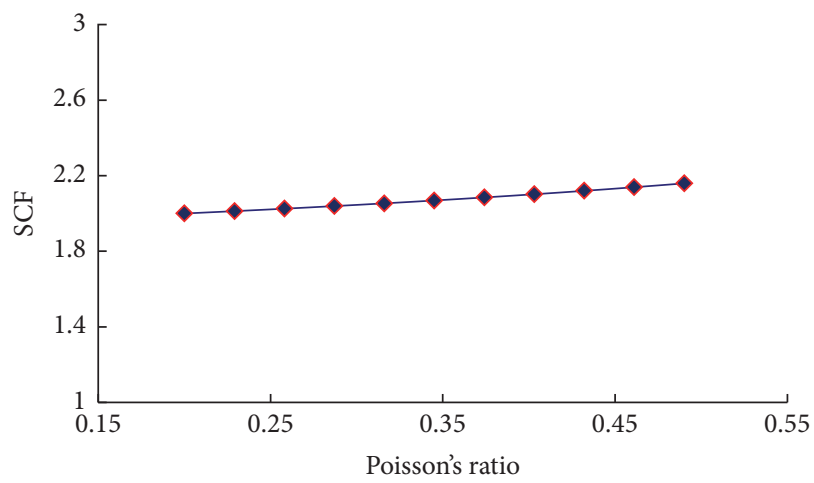

FIGURE 4: The relationship between the stress concentration factor and Poisson's ratio.

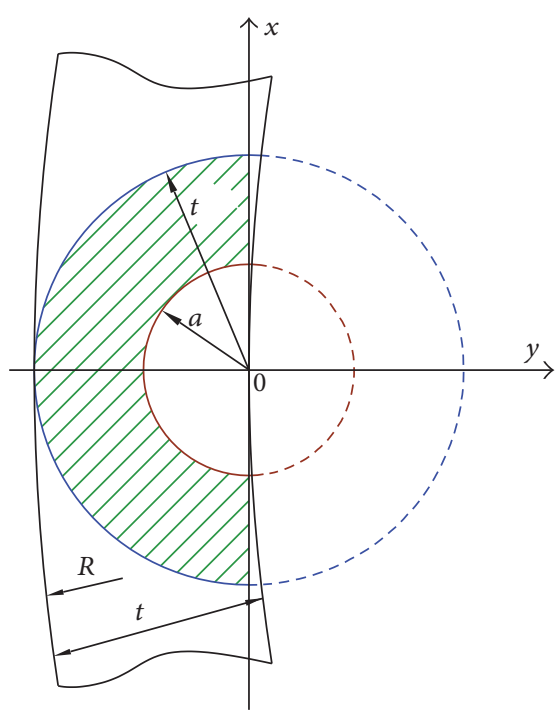

FIgURE 5: Exact-hemispherical corrosion pit. 


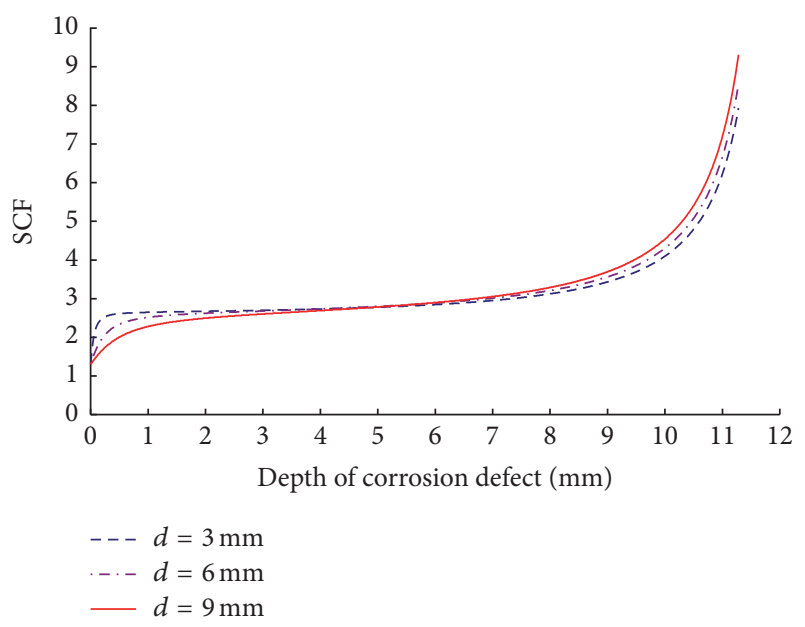

FIGURE 6: SCF change with the depth of corrosion pit.

where $v$ is Poisson's ratio of metal; $a$ is the radius of the pit; $t$ is the wall thickness.

Based on the formulas presented by Wang [4], take the casing of API $9-5 / 8^{\prime \prime} \times 11.99 \mathrm{~mm}$ as an example, assuming the diameters of pits are $d=3 \mathrm{~mm}, d=6 \mathrm{~mm}$, and $d=9 \mathrm{~mm}$, respectively ( $d$ refers to the opening of the corrosion pit, which is equal to $2 a$ in Figure 5). The SCF of spherical defects changes with the depth of pits as shown in Figure 6.

The results show that the SCF of corrosion pits mainly depends on the depth of corrosion pits, and the opening diameter has a little effect on SCF. Usually, the SCF of 2.0 is chosen as an approximate value for most stress concentration calculation cases.

\section{Stress Concentration Enhanced by Double Pits}

ASME B31G standard [7] recommends that when the critical distance is more than $2.54 \mathrm{~cm}$ ( 1 inch), the stress distributions of the two corrosion pits do not affect each other. In fact, multipoint corrosion usually occurs in downhole string; the distance between pits is often less than $2.54 \mathrm{~cm}$, as shown in Figure 1. There are multiple corrosion pits along the pipe length direction. When corrosion pits are relatively close, the stress influence between corrosion pits must be considered.

Wang and Yang [8] studied the stress concentration enhanced effect of shallow hemispherical double pits in the plate surface by three-dimensional photoelastic technique. Experimental material is epoxy resin, the size of the plate is $140 \times 70 \times 20 \mathrm{~mm}$, opening diameter is $30 \mathrm{~mm}$, depth of pit is $8 \mathrm{~mm}$, Poisson's ratio is $v=0.47$, and the ratios of $L / R$ (the center distance of the two pits to the pits radius) were 3.0, 2.0, 1.5 , and 1.0, respectively. Tensile load was applied in the $x$-axis direction, as shown in Figure 7. Stress concentration factor along the pit surface curve was obtained by slicing parallel to the $y-z$ plane after stress freezing. The testing results are shown in Table 1.

In Table 1, the results are obtained by testing a photoelastic material where Poisson's ratio is 0.47 . According to W. D.
Pilkey and D. F. Pilkey's study [6], the relationship between Poisson's ratio of material and SCF can be calculated by the following formula:

$$
K_{2}=K_{1} \times \frac{1.5\left(9-5 v_{2}\right) /\left(7-5 v_{2}\right)-1}{1.5\left(9-5 v_{1}\right) /\left(7-5 v_{1}\right)-1},
$$

where $K_{2}$ is stress concentration factor of the target material; $v_{2}$ is Poisson's ratio of the target material; $K_{1}$ is stress concentration factor of the known material; $v_{1}$ is Poisson's ratio of the known material.

Poisson's ratio of oil casing steel is $0.28\left(v_{2}\right)$, and the calculated stress concentration factors of steel are shown in Table 2 .

According to the SCF values in Table 2, the corresponding curves are shown in Figure 8. The stress concentration at the outer edges of double pits is less affected by the center distance of double pits; stress concentration factor basically remains below 1.5. The SCFs at the double pits bottom are higher than at the single pit bottom; the SCF values are 1.75. Stress values on the bottom are increased after the double pits intersection. When the two pits are far from each other $(L / R=3.0)$, maximum stress appears at the pits bottom; when two pits move closer (tangential with $L / R=2.0$ or intersecting with $L / R=1.5$ ), both of the bottom stress and the edge stress are increased. The maximum stress appears at the tangency line (intersection line). This is due to the sudden shape changing in the cross section. However, when the two pits get closer $(L / R=1.0)$, the stresses are decreased both at the intersection line and at the pits bottoms. The maximum stress still appears at the tangency line.

\section{Discussions}

In practice, double or multiple corrosion pits are common to be observed in oil and gas transportation casing, tubing, or pipeline (as shown Figure 1), and high stress could accelerate corrosion kinetics [9]. Therefore, the stress concentration enhanced by the double pits needs to be considered. The SCF value of 2.6 (Figure 8 ) is recommended to modify the SCF analytical model. The stress concentration strengthening correction coefficient of double pits in the analytic expression is

$$
f=\frac{2.6}{2.0}=1.3 \text {. }
$$

Thus, the calculation model should be expressed:

$$
K_{r}=f K_{c, \text { hemisphere }}
$$

Given that the diameters of the corrosion pits are $9 \mathrm{~mm}$ (casing type: API $9-5 / 8^{\prime \prime} \times 11.99 \mathrm{~mm}$ ), the modified SCF changes with the depth of corrosion pits as shown in Figure 9.

The stress concentration factor caused by corrosion pits can be applied to estimate internal pressure strength reduction of casing. The stress concentration factor of double 


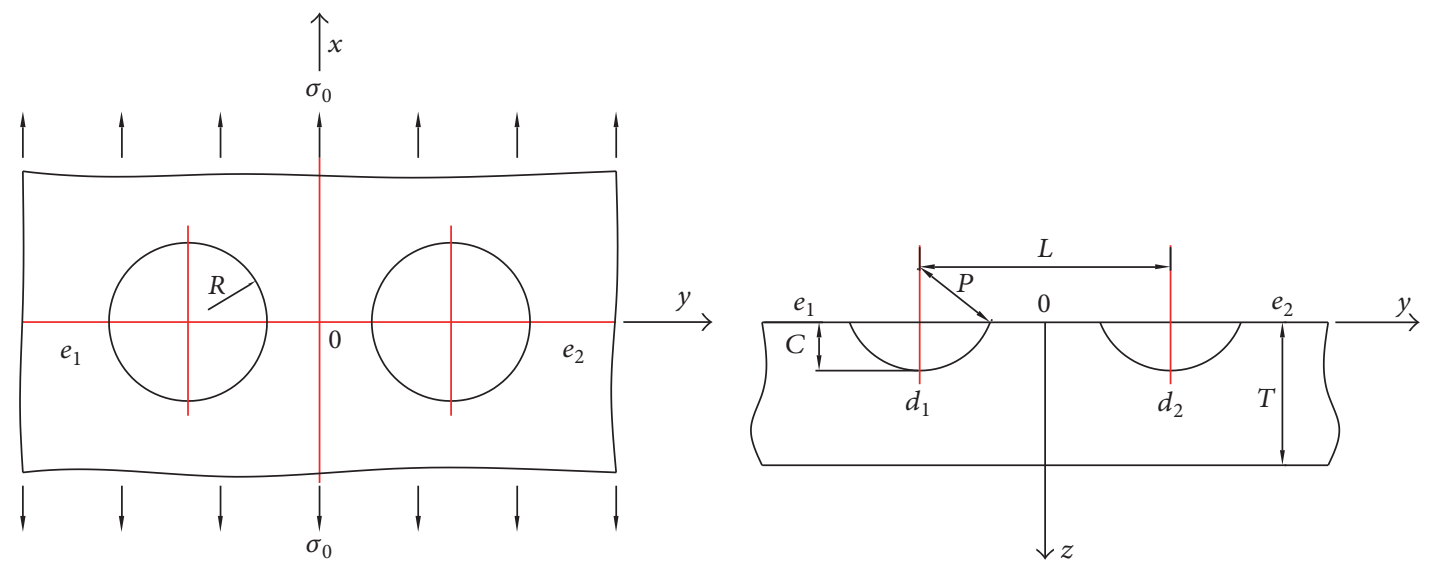

FIGURE 7: Shallow-spherical double pits stress concentration photoelastic experiment model.

TABLE 1: Results of photoelastic experiment.

\begin{tabular}{|c|c|c|c|c|c|c|c|c|c|}
\hline \multirow{2}{*}{ Category } & \multirow{2}{*}{$\begin{array}{c}\text { Center distance ratio } \\
L / R\end{array}$} & \multicolumn{3}{|c|}{ Outer edges } & \multicolumn{3}{|c|}{ Pits bottom } & \multirow{2}{*}{ Junction $K_{o}$} & \multirow{2}{*}{$K_{\max }$} \\
\hline & & $K e_{1}$ & $\mathrm{Ke}_{2}$ & Average & $K d_{1}$ & $K d_{2}$ & Average & & \\
\hline \multirow[t]{2}{*}{ Single pit } & 0 & 1.22 & 1.20 & 1.21 & & & 1.93 & & 1.93 \\
\hline & 1.0 & 1.72 & 1.65 & 1.68 & 2.26 & 2.26 & 2.26 & 2.40 & 2.40 \\
\hline \multirow{3}{*}{ Double pits } & 1.5 & 1.75 & 1.72 & 1.74 & 2.42 & 2.37 & 2.40 & 2.83 & 2.83 \\
\hline & 2.0 & 1.55 & 1.52 & 1.54 & 2.22 & 2.23 & 2.23 & 2.79 & 2.79 \\
\hline & 3.0 & 1.50 & 1.45 & 1.48 & 2.05 & 2.12 & 2.09 & 1.30 & 2.09 \\
\hline
\end{tabular}

TABLE 2: Double pits stress concentration factor of steel (calculated).

\begin{tabular}{|c|c|c|c|c|c|c|c|c|c|}
\hline \multirow{2}{*}{ Category } & \multirow{2}{*}{$\begin{array}{c}\text { Center distance ratio } \\
L / R\end{array}$} & \multicolumn{3}{|c|}{ Outer edges } & \multicolumn{3}{|c|}{ Pits bottom } & \multirow{2}{*}{ Junction $K_{o}$} & \multirow{2}{*}{$K_{\max }$} \\
\hline & & $K e_{1}$ & $\mathrm{Ke}_{2}$ & Average & $K d_{1}$ & $K d_{2}$ & Average & & \\
\hline \multirow[t]{2}{*}{ Single pit } & 0 & 1.10 & 1.09 & 1.09 & & & 1.75 & & 1.75 \\
\hline & 1 & 1.56 & 1.49 & 1.52 & 2.04 & 2.04 & 2.04 & 2.17 & 2.17 \\
\hline \multirow{3}{*}{ Double pits } & 1.5 & 1.58 & 1.56 & 1.57 & 2.19 & 2.14 & 2.17 & 2.56 & 2.56 \\
\hline & 2 & 1.40 & 1.37 & 1.39 & 2.01 & 2.02 & 2.02 & 2.52 & 2.52 \\
\hline & 3 & 1.36 & 1.31 & 1.34 & 1.85 & 1.92 & 1.89 & 1.18 & 1.89 \\
\hline
\end{tabular}

corrosion pits is represented as $K_{r}$. The revised casing burst pressure prediction model is as follows:

$$
p_{b}=0.875 \times 2 \sigma_{s}\left(\frac{1}{d_{0}}\right) \frac{1}{K_{r}} .
$$

Taking casing API $9-5 / 8^{\prime \prime}-\mathrm{N} 80$ as an example, the outer diameter is $244.47 \mathrm{~mm}$, the thicknesses are $7.92 \mathrm{~mm}$, $10.03 \mathrm{~mm}$, and $11.99 \mathrm{~mm}$, respectively, and the yield strength is $552 \mathrm{MPa}$, assuming that the opening diameter of corrosion pits in pipe wall is $6 \mathrm{~mm}$. The stress concentration factor and the casing burst pressure change with the increasing of corrosion pits depth are shown in Figures 10 and 11, respectively.

The calculation results show that when the pits' diameter is fixed, the degree of stress concentration intensifies with increasing depth of corrosion pit, and when the pit depth reaches half of the wall thickness, the SCF factor increases rapidly. Stress concentration has a significant influence on casing strength. In the downhole casing anticorrosion and strength design, stress concentration induced by the double corrosion pits needs to be considered reasonably.

\section{Conclusions}

Stress concentration enhanced by double corrosion pits in casing inner surface was studied in this paper. The conclusions were obtained as follows:

(1) The analytical SCF results show that the SCF of a hemispherical corrosion pit is primarily related to the pit depth, and the diameter of opening has a little impact on SCF. The SCF of 2.0 is used commonly in most cases.

(2) Double or multiple corrosion pits are common in practice, and the distance between the two pits will change with time during the corrosion process. The SCF strongly depends on pits distance. A correction 


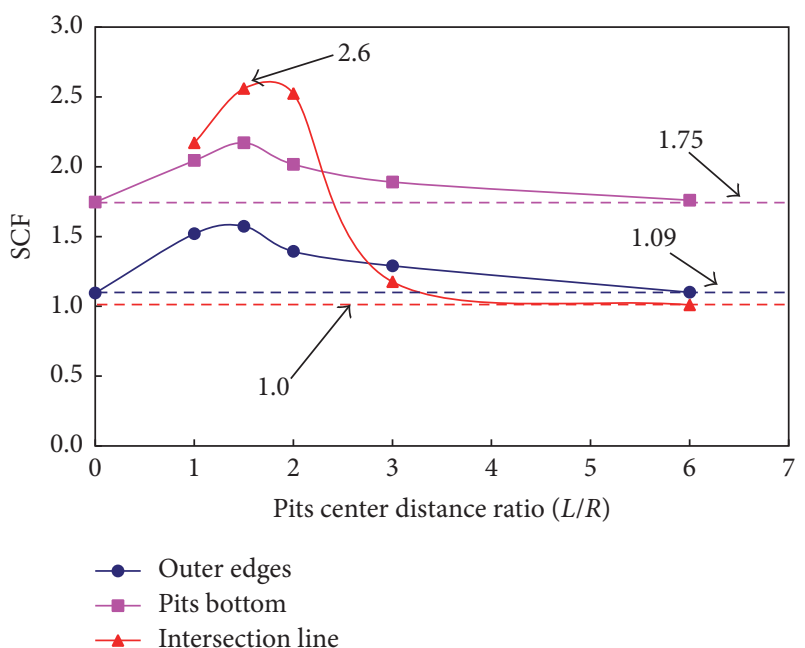

FIGURE 8: The relationship between stress concentration factor and cavity spacing of steel.

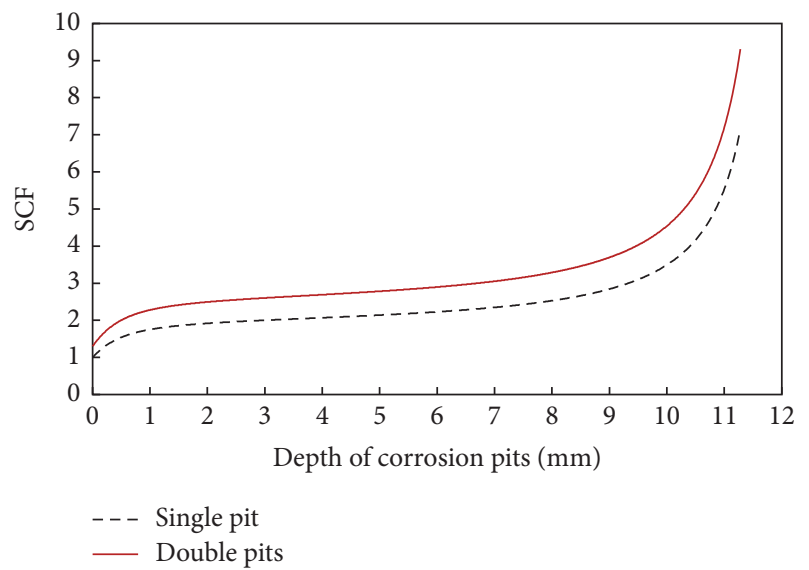

FIGURE 9: Modified SCF changing with the depth of corrosion pits $(d=9 \mathrm{~mm})$.

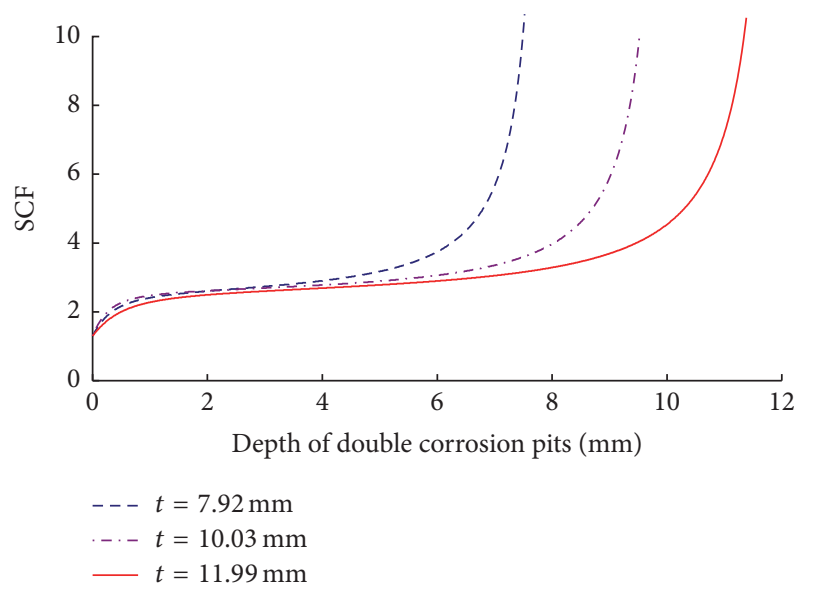

FIGURE 10: The relationship between pits depth and SCF.

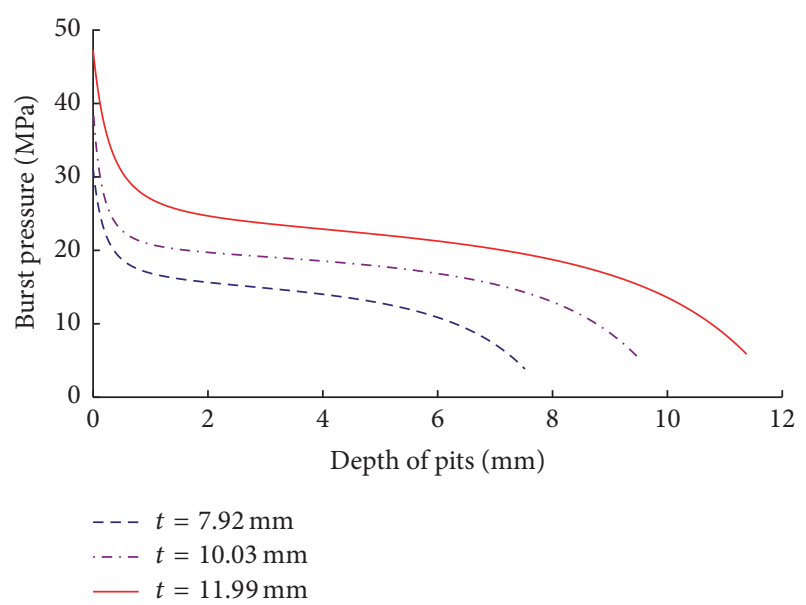

FIgURE 11: The relationship between pit depth and burst pressure.

factor of 1.3 was recommended in the double pits SCF prediction model.

(3) The stress concentration factor caused by corrosion pits can be applied to estimate internal pressure strength reduction of casing. When the depth of pit reaches half of the wall thickness, the SCF factor will increase faster. Stress concentration can degrade the casing strength obviously.

\section{Symbols}

v: $\quad$ Poisson's ratio

$v_{1}$ : $\quad$ Poisson's ratio of the known material

$v_{2}$ : Poisson's ratio of the target material

a: $\quad$ Radius of the pit

$r$ : Center distance between the corrosion pits

$\sigma_{z}: \quad$ Stress at $z$ axis

$K: \quad$ Stress concentration factor

$K_{c \text {,hemisphere }}$ SCF of a hemispherical defect model

$K_{1}$ : $\quad$ Stress concentration factor of the known material

$K_{2}$ : $\quad$ Stress concentration factor of the target material

$K_{r}: \quad$ Correction SCF of double pits.

\section{Competing Interests}

The authors confirm that this article's content has no competing interests.

\section{Acknowledgments}

This work was financially supported by the National Science Foundation of China (Grant no. 51504267).

\section{References}

[1] Y. Murakami, Stress Intensity Factor Handbook, Pergamon Press, Elmsford, NY, USA, 1987. 
[2] S. P. Timoshenko and J. M. Gere, Theory of Elastic Stability, Dover Publications, 2nd edition, 2009.

[3] K. Sun, B. Guo, and A. Ghalambor, "Casing strength degradation due to corrosion-applications to casing pressure assessment," in Proceedings of the IADC/SPE Asia Pacific Drilling Technology Conference and Exhibition, Paper No. 88009, Society of Petroleum Engineers, 2004.

[4] Q. Z. Wang, "Simple formulae for the stress concentration factor for two-and three-dimensional 11 holes in finite domains," Journal of Strain Analysis, vol. 37, no. 3, pp. 259-262, 2011.

[5] Q.Z. Wang, "High-accuracy expressions of stress concentration factor and stress intensity factor in finite domains," Journal of Mechanical Strength, vol. 23, no. 3, pp. 358-361, 2001 (Chinese).

[6] W. D. Pilkey and D. F. Pilkey, Peterson's Stress Concentration Factors, John Wiley \& Sons, New York, NY, USA, 3rd edition, 2008.

[7] SME B31G-2009, Manual for Determining the Remaining Strength of Corroded Pipelines, American Society of Mechanical Engineers, New York, NY, USA, 2009.

[8] J. H. Wang and T. C. Yang, "Stress concentration in slab caused by two or more shallow spherical hollows," Journal of Experimeantal Mechanics, vol. 9, no. 3, pp. 270-274, 1994 (Chinese).

[9] P. Zhu, W. Yan, L. Deng, and J. Deng, “The application of mechanical-chemical corrosion theory in downhole tubing $\mathrm{CO}_{2}$ corrosion research," Advances in Materials Science and Engineering, vol. 2015, Article ID 296278, 6 pages, 2015. 

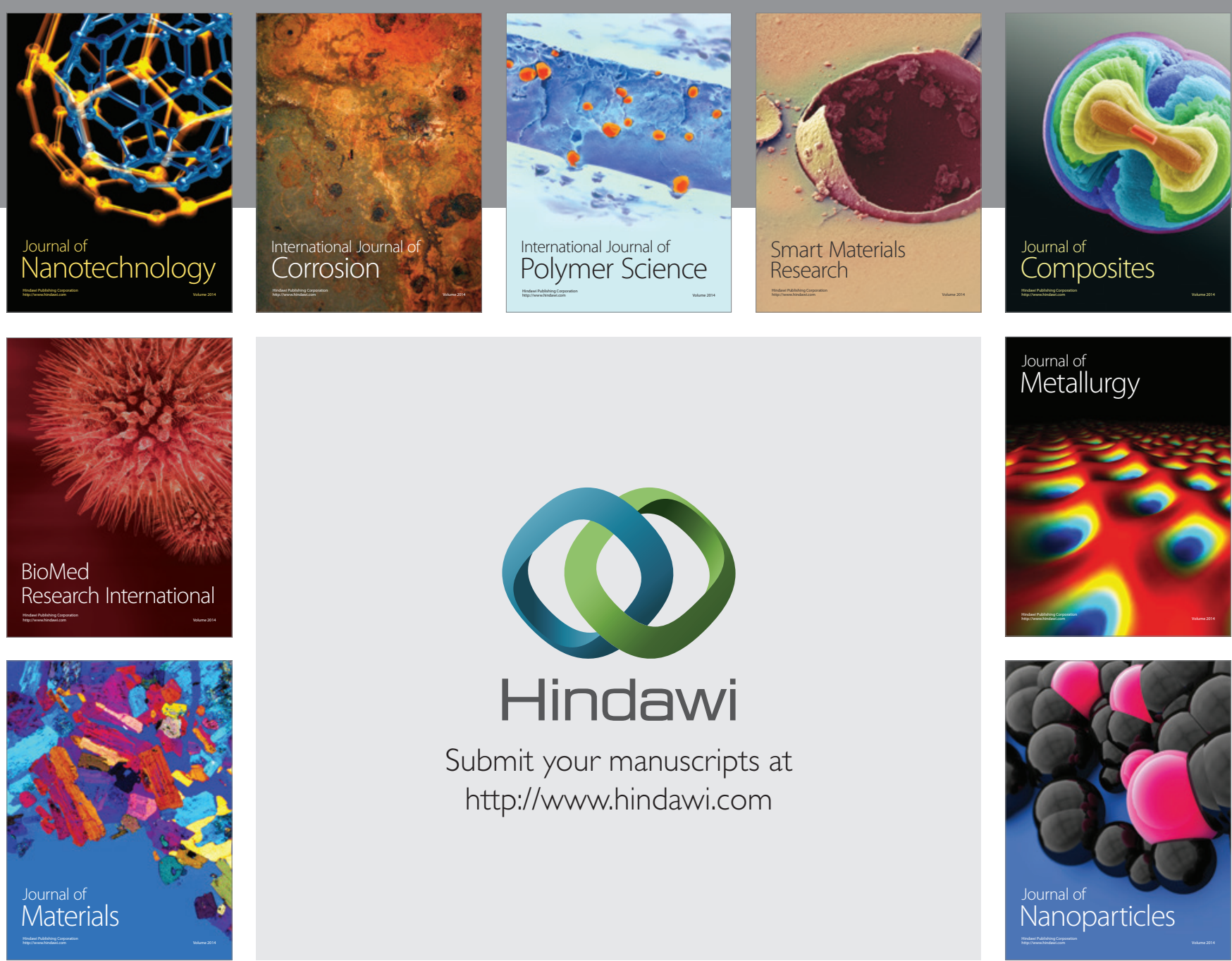

\section{Hindawi}

Submit your manuscripts at

http://www.hindawi.com

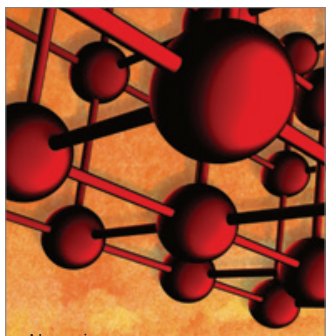

Materials Science and Engineering
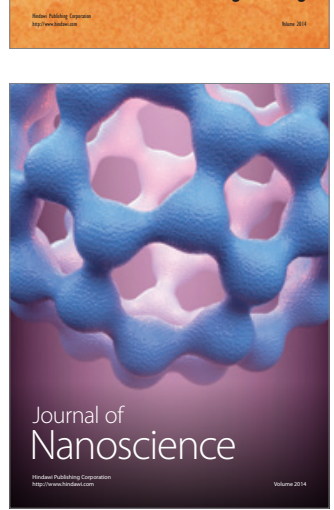
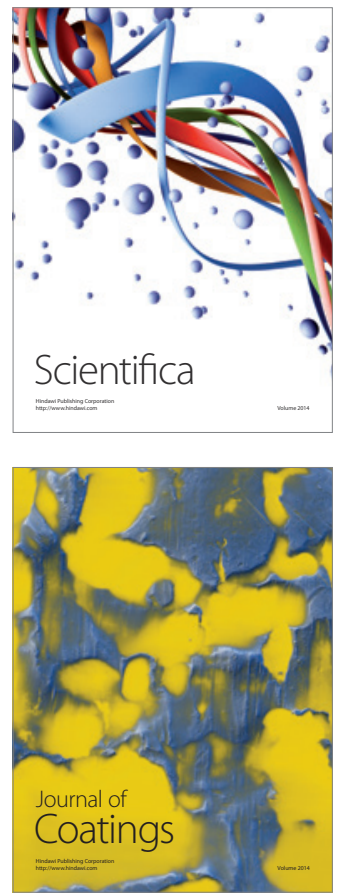
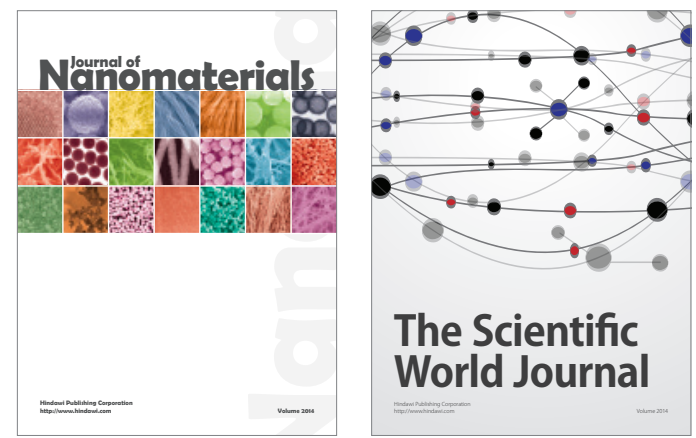

The Scientific World Journal
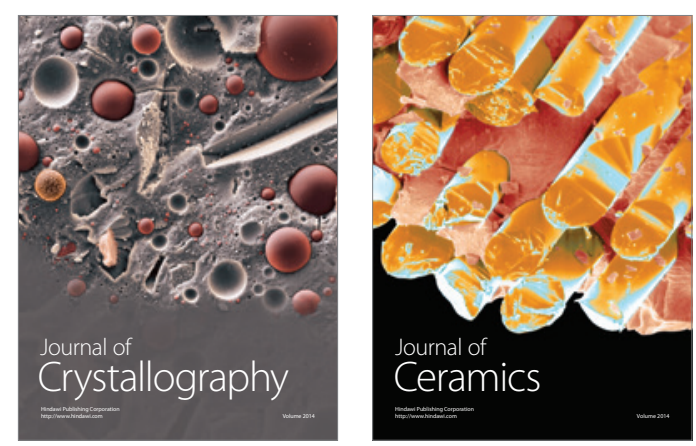
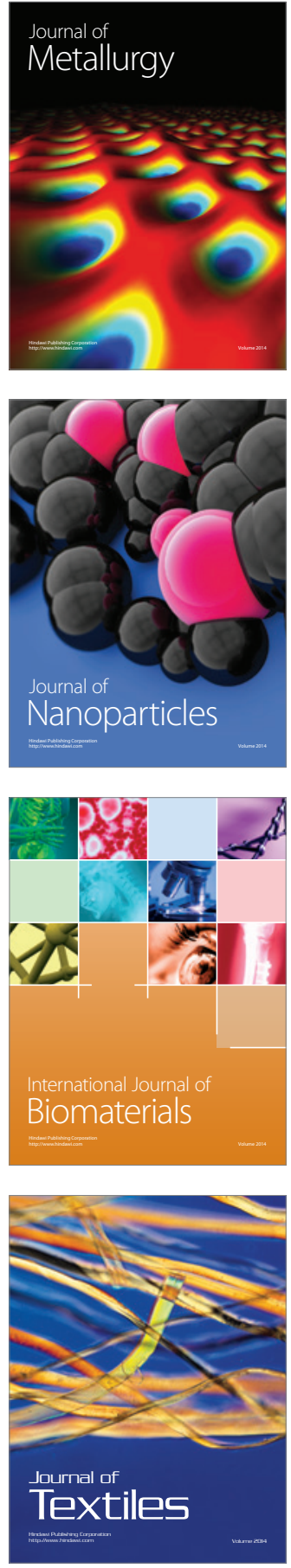